\title{
Correction to: Analysis and implementation of reactive fault tolerance techniques in Hadoop: a comparative study
}

\author{
Hassan Asghar ${ }^{1,2} \cdot$ Babar Nazir ${ }^{1,3}$
}

Published online: 11 February 2021

(c) Springer Science+Business Media, LLC, part of Springer Nature 2021

\section{Correction to: The Journal of Supercomputing https://doi.org/10.1007/s11227-020-03491-9}

Due to problems during production the author information was incorrectly published.

The correct author information reads:

Hassan Asghar ${ }^{1,2}$, Babar Nazir ${ }^{1,3}$

${ }^{1}$ Department of Computer Science, COMSATS University Islamabad, Abbottabad Campus, Abbottabad, KPK, Pakistan

${ }^{2}$ Department of Software and Communications Engineering, Hongik University, Sejong, South Korea

${ }^{3}$ Department of IT and Computer Science, Pak-Austria Fachhochschule: Institute of Applied Sciences and Technology, Haripur, KPK, Pakistan

The original article has been corrected.

Publisher's Note Springer Nature remains neutral with regard to jurisdictional claims in published maps and institutional affiliations.

The original article can be found online at https://doi.org/10.1007/s11227-020-03491-9.

Babar Nazir

babarnazir@gmail.com

Hassan Asghar

haxxanasghar@gmail.com

1 Department of Computer Science, COMSATS University Islamabad, Abbottabad Campus, Abbottabad, KPK, Pakistan

2 Department of Software and Communications Engineering, Hongik University, Sejong, South Korea

3 Department of IT and Computer Science, Pak-Austria Fachhochschule: Institute of Applied Sciences and Technology, Haripur, KPK, Pakistan 